\title{
Update on pathogenesis and immunology of Graves' ophthalmopathy
}

\author{
LARYSA KRAJEWSKA-WĘGLEWICZ1, DOROTA M. RADOMSKA-LEŚNIEWSKA², \\ MAEGORZATA DOROBEK $K^{3}$, JUSTYNA IZDEBSKA ${ }^{4}$, ANNA IWAN ${ }^{2}$, ANNA HYC \\ ANNA M. AMBROZIAK ${ }^{5,6}$, PIOTR SKOPIŃSKI
}

${ }^{1}$ Department of Ophthalmology, Central Clinical Hospital of Ministry of the Interior and Administration, Warsaw, Poland
${ }^{2}$ Department of Histology and Embryology, Medical University of Warsaw, Warsaw, Poland
${ }^{3}$ Department of Neurology, Central Clinical Hospital of Ministry of the Interior and Administration, Warsaw, Poland
${ }^{4}$ Department of Ophthalmology, Medical University of Warsaw, Warsaw, Poland
${ }^{5}$ Department of Information Optics, Institute of Geophysics, Faculty of Physics, University of Warsaw, Warsaw, Poland
${ }^{6}$ Eye World, Ophthalmological Centre, Warsaw, Poland

\begin{abstract}
Graves' ophthalmopathy $(G O)$ is an inflammatory autoimmune disorder of the orbital adipose tissue and extraocular muscles, and it is associated with Graves' disease (GD). GO is triggered by binding and activation of orbital fibroblasts by autoantibodies (TSI) direct against thyroid-stimulating hormone receptor (TSHR) and insulin-like growth factor $1(I G F-1 R)$, which is highly expressed within the orbit. Moreover, interaction of T cells with orbital fibroblasts that involve T-cell receptor (TCR), autoantigen, and major histocompatibility complex class II (MHC II) molecule, as well as CD40:CD154 signalling, activates p38, ERK 1/2, and JNK pathways. These processes induce fibroblast activation, proliferation, and secretion of chemokines and inflammatory cytokines to maintain inflammation within the orbit. Furthermore, increased hyaluronic acid production and fibroblast differentiation into adipocytes and myofibroblasts leads to development of GO. The elevated number of molecular factors such as PDGF, IL1- $\beta, I L-4, I L-6, I L 10, I L-8, I L-16, I L-33, H G F$, ICAM-1, osteopontin, CTLA-4, and TGF- $\beta$ are discussed in the paper. Some of them are key markers of disease stage. Better understanding of GO pathogenesis leads to development of new therapeutic options.
\end{abstract}

Key words: Graves' disease, Graves' ophthalmopathy (GO), orbital fibroblast, thyroid-stimulating hormone receptor (TSHR), thyroid-stimulating antibodies (TSI).

(Centr Eur J Immunol 2018; 43 (4): 458-465)

\section{Introduction}

Graves' ophthalmopathy (GO) is an inflammatory autoimmune disorder of the orbital adipose tissue and extraocular muscles. The critical clinical signs are retraction of upper eyelid and axial proptosis with variable restriction of eye movements (often extraocular muscles are involved). Conjunctival and corneal inflammatory complications may also occur. It is associated with Graves' disease (GD) [1, 2].

A major role in the development of this condition is played by autoimmunity of T cells, B cells, macrophages, fibroblasts, and adipose tissue within the orbit. Cytokine-mediated inflammation in the orbit is also an important factor in its development [2]. The most common and important extrathyroidal manifestation of GD is GO [1]. In most cases, it occurs in patients with active or past hyperthyroidism but may rarely develop in patients who are euthyroid or even in a hypothyroid state [3]. About 50-70\% of patients with GD have mild (or subclinical) symptoms, whereas $3-5 \%$ of patients show sight-threatening symptoms of significant GO with exophthalmos and pain [2, 4]. The latter represents an emergency requiring immediate treatment. Sight loss in those cases may be due to corneal ulceration or to dysthyroid optic neuropathy (DON), which occurs more frequently [5].

The estimated incidence of GO is $16 / 100,000$ women and 3/100,000 men [6, 7].

\section{The molecular mechanism of Graves' ophthalmopathy}

GD hyperthyroidism is caused by autoantibodies (GD$\mathrm{IgG})$ directed against thyroid-stimulating hormone receptor (TSHR). These autoantibodies activate the receptor and stimulate thyroid follicular hypertrophy, which leads to excessive hormone production [4]. The pathogenesis

Correspondence: Prof. Dorota M. Radomska-Leśniewska, Department of Histology and Embryology, Medical University of Warsaw, 5 Chalubinskiego St., 02-004 Warsaw, Poland, e-mail: dradomska@wum.edu.pl

Submitted: 16.11.2018; Accepted: 6.12.2018 
of GO is not fully understood. TSHR is highly expressed within the orbit. This points out their potential role in the development of GO [4]. GD-IgG activation of TSHR on fibroblasts, preadipocytes, and adipocytes in the soft tissue of the orbit is considered as a major factor in the pathogenesis of GO. However, GD-IgG may also directly activate IGF-1 receptors (IGF-1Rs) on these cells and support development of GO [8, 9]. GD-IgG and insulin-like growth factor-1 (IGF-1) increase secretion of regulated on activation, normal $\mathrm{T}$-cell expression and secretion
(RANTES), and IL-16, which intensify T-cell migration into the orbit. T lymphocytes interact with orbital fibroblasts via a specific CD40:CD154 molecular bridge leading to fibroblast activation, proliferation, and differentiation into myofibroblasts and adipocytes [8-10]. Activated fibroblasts produce GAG in excess, undergo adipogenesis, and secrete pro-inflammatory cytokines including IL- $1 \alpha$, IL-1 $\beta$, IL-6, IL-8, macrophage chemoattractant protein-1 (MCP-1), and transforming growth factor- $\beta$ (TGF- $\beta$ ), to maintain inflammation within the orbit (Fig. 1). Molecular

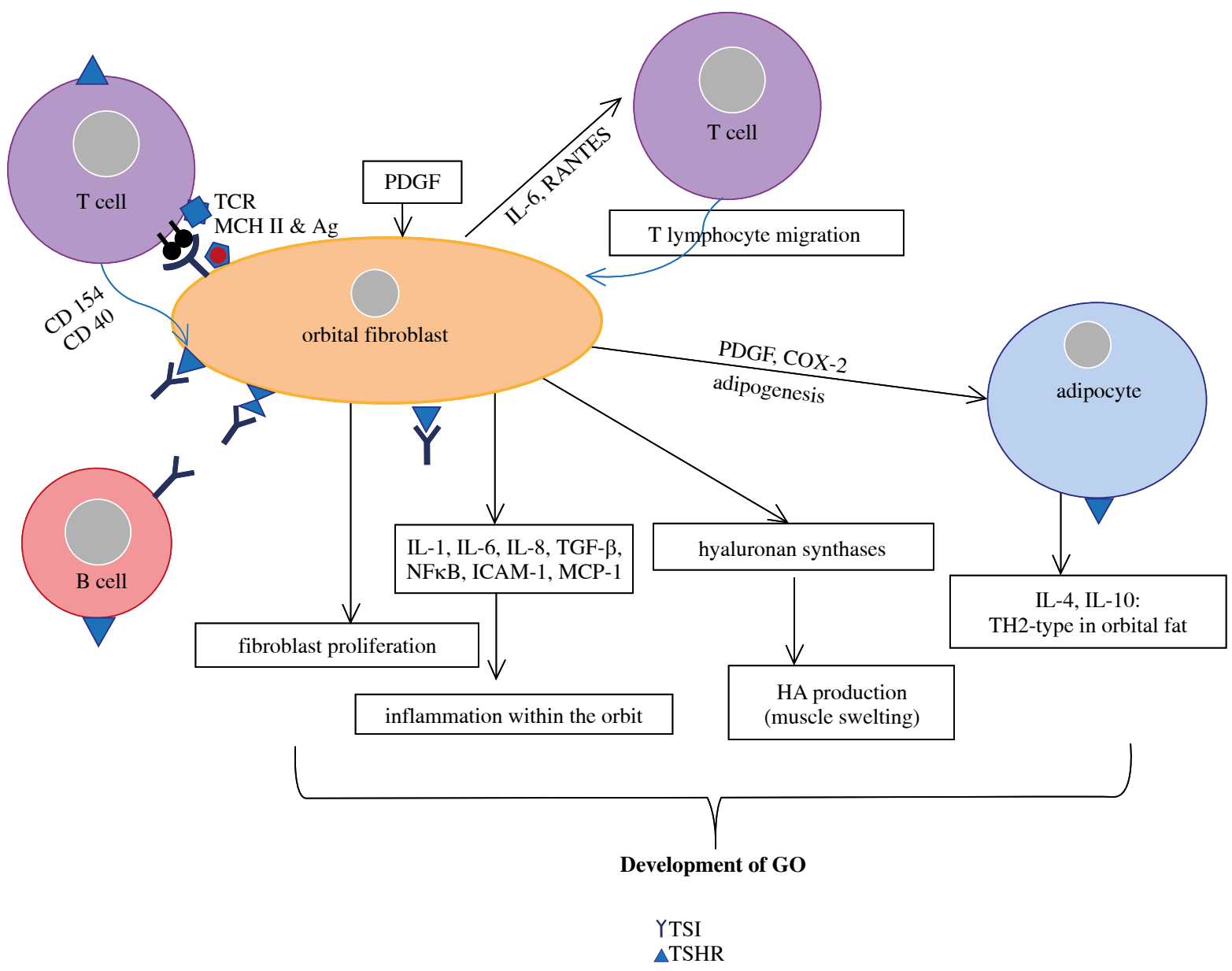

GO is triggered by binding and activation of orbital fibroblasts by autoantibodies called thyroid-stimulating antibodies (TSI) directed against thyroid-stimulating hormone receptor (TSHR), which is highly expressed within the orbit. TSI and insulin-like growth factor-1 (IGF-1) increase secretion of Regulated on Activation, Normal T Cell Expression and Secretion (RANTES) and IL-16, which elevates T-cell migration into the orbit.

Helper T cells recognise TSHR peptides located on orbital fibroblasts and lead to the activation and ligation of TSHR by TSI. This process induces fibroblast activation, proliferation, and secretion of chemokines, inflammatory cytokines, as well as increased hyaluronic acid production and adipogenesis. Moreover, interaction of T cells with orbital fibroblast that involves T-cell receptor (TCR), autoantigen, and major histocompatibility complex class II (MHC II) molecule as well as CD40:CD154 signalling activates p38, ERK 1/2, and JNK pathways, leading to increased secretion of ICAM-1, NFKB, Il-6, Il-8, and MCP-1, as well as hyaluronan (HA) production, to maintain inflammation within the orbit. Activated orbital fibroblasts proliferate and differentiate into adipocytes and myofibroblasts. Adipogenesis is also induced by IL- $1 \beta$ through an increase of cyclooxygenase-2 (COX-2). IGF-1R, just like TSHR, can be activated by TSI via PI3K/ACT pathways, upregulating peroxisome proliferator-activated receptor- $\gamma(\mathrm{PPAR}-\gamma)$ expression differentiation and proliferation of adipocytes and accelerate adipogenesis. PDGF increases the TSHR expression on orbital fibroblasts and plays also an adipogenic role.

Fig. 1. Pathogenesis of Graves' ophthalmopathy (GO) 
pathways including adenylyl cyclase/cyclic adenosine monophosphate, phosphoinositide 3 kinase/AKT/mammalian target of rapamycin, and mitogen-activated protein kinase are involved in GO. At present, the development of a GO animal model and a new generation of TSHR antibody assays indicate TSHR as the primary autoantigen for GO. $\mathrm{T}$-cell infiltrates in GO orbital tissues are predominantly $\mathrm{CD}^{+}$, with some studies suggesting the presence of both $\mathrm{CD}^{+}$and $\mathrm{CD}^{+} \mathrm{T}$ cells [9-12]. Th1-like cytokine profile is expressed mainly in GO retrobulbar tissue [10-13]. Th1like cytokine expression profile consisting of interferon (IFN)- $\gamma$, tumour necrosis factor (TNF)- $\alpha$, IL-1 $\beta$, and IL-6 occurs mainly in GO extraocular muscles, whereas IL-4 and IL-10, Th2-type cytokines, are expressed in orbital fat [14]. The duration of GO plays a role in the predominance of T-cell subsets. Th1 cells dominate in the active phase of GO, and Th2 cells in the late phase [15]. Higher levels of IL-1 $\beta$, IL-6 [16], and IL-17 [17] are also observed in the active phase compared to the inactive phase. In patients with refractory GO, higher levels of IL-4, IL-6, and IL-10 are seen, compared to those seen in patients in remission [18]. Steroid treatment causes an increase in the level of IL-16 and a decrease of IL-8 [19, 20]. A role in the development of GO may also be played by IL-10 as well as IL-2 polymorphism [20]. The levels of interleukin 2 [21], IL-16 [22], and IL-33 [23] are elevated in the blood of GO patients compared to those of the controls. Serum IL-33 levels are positively correlated with T3 and T4, but they are negatively correlated with TSH [22]. Serum hepatocyte growth factor (HGF) is increased in GO patients compared to that in control subjects, as well as responses to efficient glucocorticoid treatment [19]. Intercellular adhesion molecule-1 (ICAM-1) and soluble vascular cell adhesion molecule-1 (sVCAM-1) are adhesion molecules that play a role in cell/cell or cell/extracellular matrix interaction, activation, and migration. They are increased in the blood of GO patients as compared to those in control patients. Their levels seem also to be responsive to the treatment [23]. Osteopontin [24, 25], a protein involved in inflammation, cell recruitment, cell adhesion, and remodelling, is considered to be involved in GO development. It is inversely correlated with TSH level and positively with T3 and T4 [25]. Another protein called cytotoxic $\mathrm{T}$ lymphocyte-associated antigen-4 (CTLA-4), a member of the immunoglobulin superfamily, which is found on T-cell surface, is negatively correlated with these cells. Polymorphism of CTLA-4 gene may lead to autoimmune diseases [26-28]. Moreover, HLA-B8, an MHC class I cell surface receptor, may be associated with GO development, but its role remains to be elucidated $[29,30]$. In the orbital fat in smokers with GO elevated levels of IL- $1 \beta$ and IL-6 seem to be associated [31]. Transforming growth factor- $\beta$ (TGF- $\beta$ ) and fibroblast growth factor (FGF) are elevated in the orbital fat of GO patients, and levels of these factors are correlated with the severity of the disease. Platelet-de- rived growth factor (PDGF) is probably the most important among all growth factors in the GO pathological events. It is overexpressed in orbital tissue of GO patients, which was observed in several studies [32-34], independently of the activity grade of GO. Specific isoforms of PDGF increase the TSH-R expression on orbital fibroblasts, amplifying the autoimmune response against TSH-R [32]. Drugs blocking PDGF signalling may be new therapeutic options $[34,35]$. Some of the latest studies indicate that PDGF plays an adipogenic role by transforming orbital fibroblasts into adipocytes [36]. Adipogenesis is also induced by IL-1 $\beta$ through an increase of cyclooxygenase-2 (COX-2). It is an inflammation modulating enzyme and is anticipated to be a central element of the active phase of GO. Its mRNA and protein levels have been shown to be overexpressed in orbital fibroblasts of GO patients [37], and hyaluronic acid (HA) seems to be involved in its regulation. However, other studies did not confirm any modification of its expression [38]. TGF- $\beta$ receptor, IGF-1, and insulin-like growth factor binding protein-6 (IBP-6) seem to be downregulated [39].

Contact of T-cell receptor with major histocompatibility complex class II (MHC II) molecule and CD40:CD154 signalling leads to proliferation of orbital fibroblasts. Proliferation of orbital fibroblasts may be inhibited by blocking antibodies to MHC II, CD40, and CD40 ligand (CD154). IFN- $\gamma$ mediated through Jak2 upregulates expression of CD40 in orbital fibroblasts [16].

Ligation of CD40 with CD154 leads to increased secretion of intercellular adhesion molecule-1 (ICAM-1) [17] and nuclear translocation of nuclear factor- $\kappa \beta$ (NF$\kappa \beta)$ [40], IL-6, IL-8, and MCP-1 in GO orbital fibroblasts compared with normal controls [41]. CD40 upregulates IL-1 $\alpha$ secretion, and HA and PGE2 synthesis [42]. Ligation of CD40:CD154 induces all three mitogen-activated protein kinase (MAPK) pathways, p38, ERK1/2, and JNK, which are engaged in gene expression, cellular proliferation, differentiation, and apoptosis.

ICAM expression is mainly P38 MAPK and NF- $\kappa \beta$ dependent, whereas ERK1/2 and JNK also activate the $\mathrm{NF}-\kappa \beta$ pathway, a transcription factor pathway that regulates genes involved in immune and inflammatory responses [43].

\section{Orbital fibroblasts}

Orbital fibroblasts have some unique features, including their strong response to cytokines [44], and high levels of inflammatory mediators such as prostaglandins [42, 45-47], lipoxygenase products [48], and chemokines [49]. This may be the background of clinically aggressive GO.

They produce a diverse array of both Th1 and Th2 cytokine types [50, 51]. Orbital fibroblasts express all three isozymes of hyaluronan synthase [52] and the upstream enzyme, UDP-glucose dehydrogenase [29, 30]. Those en- 
zymes are involved in the biosynthesis of the glycosaminoglycan and hyaluronan. Orbital fibroblasts, especially those from patients with GO, consist of heterogeneous cell populations and are divided into subsets based on the display of the glycoprotein Thy-1 [44, 53, 54]. In regard to the expression of this surface marker, cells can differentiate into mature adipocytes (Thy- $1^{-}$) and those that can eventually form myofibroblasts $\left(\right.$ Thy- $\left.1^{+}\right)$. Thy- 1 expression may be, at least in part, responsible for expansion of the orbital connective tissue contents and its extensive fibrosis. However, many studies conducted in order to characterise orbital fibroblasts neglected their phenotypic and functional diversity.

Douglas et al. explored the cellular makeup of the orbit in GO [55]. They identified the increased levels of a subset of circulating $\mathrm{CD} 34^{+}$cells that infiltrate the orbit in GO and express high levels of functional TSHR. Fibrocytes are $\mathrm{CD} 34^{+}$cells that derive from the bone marrow. Normally, fibroblasts inhabiting orbital connective tissue are uniformly $\mathrm{CD}^{-} 4^{-}$. Fibrocytes in GO appear to partially replace the fibroblasts. They can differentiate into either fat cells or myofibroblasts, which may be responsible for tissue remodelling patterns found in GO [55]. It seems that fibrocytes also infiltrate the thyroid in GD and may be an important link between the orbit and the thyroid.

\section{TSHR}

TSHR plays major role in the hyperthyroidism associated with GD. However, the role of the stimulatory antibodies directed against TSHR, often referred to as thyroid-stimulating antibodies (TSI or TSAb), in initiating or sustaining orbital tissue remodelling in GO has not been well established yet. A lot of circumstantial evidence suggests that TSHR and TSAb may be involved. General correlation appears to exist between levels of TSAb and the severity and activity of GO [56-58]. Higher cell surface levels of TSHR are found in orbital tissues from active disease and are displayed by orbital fibroblasts from these patients, especially following induction of adipogenesis [59]. These findings generally support the participation of TSHR. Detection of TSHR mRNA in orbital tissues was first reported by Feliciello et al., who found the transcript in healthy tissues and those coming from GO [60].

Parmentier et al. accomplished molecular cloning of the TSHR gene [61]. They isolated a $4.9 \mathrm{~kb}$ cDNA encoding a 744 amino acid peptide. The receptor protein represents a classical seven-membrane spanning, rhodopsin-like, G-protein-coupled protein. Its structure has been solved with crystallisation studies by the laboratory group of Reese-Smith [62, 63]. TSHR is a family member of cell surface receptors that includes luteinising hormone (LH) and follicle-stimulating hormone (FSH) [64]. It comprises a multimeric structure $[65,66]$ with the ligand-binding site located in the amino-terminus [67]. One gene encodes the receptor, which is translated into a single peptide undergoing cleavage into constituent subunits connected by a disulphide bond. The extracellular TSHR domain is cleaved by a cell surface metalloproteinase, the identity of which remains uncertain [68]. This cleaved fragment is particularly immunogenic, and its characteristics are likely to proximally underlie generation of TSI. The multimeric structure of the TSHR drives affinity maturation of the pathogenic autoantibodies in GD.

Helper T cells recognise TSHR peptides, leading to their activation and ligation of TSHR by TRAb, which induces secretion of chemokines and inflammatory cytokines, adipogenesis, and increased hyaluronic acid production. Enhanced production of connective tissue results in extraocular muscle enlargement and orbital fat expansion [69] (Fig. 1).

Levels of TSI correlate with the severity and clinical activity of the disease $[57,58]$ and high TRAb levels in early GO predict a poor prognosis [59].

Many investigations provide data showing that TSHR mRNA and protein are detectable in both GO and normal orbital tissues and fibroblast cultures. However, considerably higher levels of TSHR are found in GO cells [6971]. It has been also proven that levels of TSHR mRNA in GO orbital adipose tissue correlate with the activity of the disease, indicating a potential role of TSHR in the development of the disease [72].

Zhang et al. introduced bovine TSH or two different monoclonal TRAbs into normal and GO fibroblast cultures and demonstrated increased HA production in normal fibroblast cultures, but not in GO fibroblasts [73].

They also introduced an activating mutant TSHR into normal and GO orbital fibroblasts and observed enhanced adipocyte differentiation [73].

Nevertheless, transfecting GO orbital fibroblasts with an activating mutant TSHR leads to elevated HA production due to induction of hyaluronan synthases 1 and 2, compared with control transfected cells.

In another study, conducted by Kumar et al., of GO orbital fibroblasts treated with either bovine TSH or a potent stimulatory TSI (termed M22), elevated levels of cAMP, pAkt, and HA were found [74]. These effects could be blocked by co-treatment with a small molecule TSHR antagonist, termed C-1 [75]. Activation of this receptor leads to changes in the cellular characteristic of GO.

However, these associations between levels of anti-TSHR and disease activity/severity do not constitute proof of a causal relationship. Currently, a potential role of additional molecular determinants such as IGF-1R is being considered as a participant in the disease process [8].

The signalling downstream from TSHR is complex. It involves several distinct pathways known to crosstalk. Better apprehension of post-receptor signalling would allow identification of additional therapeutic targets. These include the potential role of proteins binding with TSHR. 
Among these are the $\beta$ arrestins [76, 77], versatile adaptor proteins that are involved in receptor internalisation and desensitisation, assisting receptor uncoupling from downstream targets, and facilitating receptor interactions with clathrin-coated pits. $\beta$-arrestins are capable of protein complex formation, which is thought to be involved in the transduction of post-receptor signalling [76, 77].

\section{Crosstalk between TSHR and IGF-IR}

IGF-I and its cognate receptor, IGF-IR, are family members of a group of molecules that play critical roles in diverse biological functions such as growth, cellular metabolism, and immunity [78]. IGF-IR is a tyrosine kinase receptor that spans the plasma membrane and connects with several down-stream signalling pathways, taking part in the regulation of many target genes [79, 80]. Pritchard et al. noticed that GD-IgGs, but not those from healthy controls, could upregulate the expression of chemokines in orbital fibroblasts [81]. That study indicates that IGFIR was over-expressed in orbital fibroblasts from patients with GD. Moreover, the FRAP/Akt/mTOR/p70S6k pathway was involved in downstream signalling and the activation by GD-IgG of chemokine expression in orbital fibroblasts from these patients, including IL-16 and regulated on activation, normal $\mathrm{T}$ cell expressed and secreted (CCL5, RANTES) [82]. The specific antagonist 1H7 could attenuate activation by rhTSH and IgGs of the downstream kinase Erk.

The same results could be achieved by transfecting cells with a dominant negative IGF-IR [81]. It has been many years since Ingbar et al. investigated the relationship between the TSHR and IGF-IR pathways. They found that IGF-I could enhance or abrogate certain actions of TSH in cultured thyroid epithelial cells [83]. However, the molecular basis for the interactions between the two pathways is still is still uncertain. Tsui et al. reported that TSHR and IGF-IR form a physical and functional complex in thyroid tissues, orbital fat, and in fibroblasts [60]. IGF-1R, just like TSHR, can be activated by TSI viaPI3K/ACT pathways, upregulating peroxisome proliferator-activated receptor- $\gamma$ (PPAR- $\gamma$ ) expression, differentiation, and proliferation of adipocytes and enhancing adipogenesis [84]. This same group found what appears to be a fragmentation of IGF-IR into polypeptide sequences containing the alpha and beta subunits [85]. IGF-IR $\beta$ co-localises with TSHR and seems to mediate the signalling initiated by TSHR, which leads to downstream activation of the Erk and FRAP/mTor/Akt/ p70s6k pathways [60]. The actions of TSH, TSI, IGF-I, and GD-IgG can be attenuated with IGF-IR inhibiting antibodies. A confirmatory study of TSHR-initiated signalling on IGF-IR was conducted recently by Krieger et al. [86]

Teprotumumab, the fully human IGF-IR blocking antibody, is a newly developed therapy for GD and GO.
This antibody has recently been evaluated for safety and efficacy in the treatment of moderate to severe active GO in a phase 2 double-masked, placebo-controlled, prospective, multicentre trial [67]. It has been shown to be capable of blocking the actions of IGF-I and both TSH and pathogenic TSIs in bone marrow-derived fibrocytes in vitro [87]. There is still the unsolved issue of the potential for side effects. These can occur frequently because of the wide array of normal physiological function that this pathway is involved in regulating, including growth and metabolism. The structural similarities shared by IGF-IR and the insulin receptor make the selective modulation of each difficult but not impossible.

\section{Newly developed molecules for directly interrupting TSHR function}

Development of small molecules as cell-surface receptor antagonists can offer specific advantages as potential therapeutics. The inverse TSHR agonist NCGC00161856 inhibits in a competitive way basal and TSH-dependent cAMP generation in HEK-EM 293 cells [88]. The molecule is able to attenuate constitutive expression of TSHR, thyroperoxidase, thyroglobulin, and sodium iodide symporter in thyroid epithelial cells and is one of the first discovered small molecule reverse agonists for TSHR. It was also shown that the agonist could inhibit basal levels of cAMP, pAkt, and hyaluronan accumulation in orbital fibroblasts [89]. Other studies, also in orbital fibroblasts, have revealed that the antagonist NCGC00229600 could block the actions of TSH and M22, the monoclonal mAb TSHR agonist [90]. NCG00229600 attenuated the increased cAMP generation provoked by M22 and TSH in orbital fibroblasts that had been differentiated into adipocytes.

\section{Conclusions}

Nowadays, anti-inflammatory treatment is mainly based on corticosteroids. Better understanding of GO pathogenesis leads to the development of new therapeutic options, e.g. biologic agents (rituximab, infliximab). There are some reports with small series of patients, in which biologic agents were used off-label. This approach showed some promising results. However, there is still much that needs to be investigated.

The authors declare no conflict of interest.

\section{References}

1. Menconi F, Marcocci C, Marinň M (2014): Diagnosis and classification of Graves' disease. Autoimmun Rev 13: 398402. 
2. Ambroziak AM, Szaflik J, Szaflik JP, et al. (2016): Immunomodulation on the ocular surface: a review. Centr Eur J Immunol 41: 195-208.

3. Bahn RS (2010): Graves' ophthalmopathy. N Engl J Med 362: 726-738.

4. Wiersinga WM, Smit T, van der Gaag R, et al. (1988): Temporal relationship between onset of Graves' ophthalmopathy and onset of thyroidal Graves' disease. J Endocrinol Invest 11: 615-619.

5. Bahn RS (2003): Clinical review 157: Pathophysiology of Graves' ophthalmopathy: the cycle of disease. J Clin Endocrinol Metab 88: 1939-1946.

6. Hiromatsu Y, Eguchi H, Tani J, et al. (2014): Graves' ophthalmopathy: epidemiology and natural history. Intern Med Tokyo Jpn 53: 353-360.

7. Bartley GB (1994): The epidemiologic characteristics and clinical course of ophthalmopathy associated with autoimmune thyroid disease in Olmsted County, Minnesota. Trans Am Ophthalmol Soc 92: 477-588.

8. Dittfeld A, Gwizdek K, Michalski M, et al. (2016): A possible link between the Epstein-Barr virus infection and autoimmune thyroid disorders. Centr Eur J Immunol 41: 297-301.

9. Smith TJ, Hegedüs L, Douglas RS (2012): Role of insulin-like growth factor-1 (IGF-1) pathway in the pathogenesis of Graves' orbitopathy. Best Pract Res Clin Endocrinol Metab 26: 291-302.

10. Wiersinga WM (2011): Autoimmunity in Graves' ophthalmopathy: the result of an unfortunate marriage between TSH receptors and IGF-1 receptors? J Clin Endocrinol Metab 96: 2386-2394.

11. Yang D, Hiromatsu Y, Hoshino T, et al. (1999): Dominant infiltration of $\mathrm{T}(\mathrm{H}) 1$-type $\mathrm{CD} 4+\mathrm{T}$ cells at the retrobulbar space of patients with thyroid-associated ophthalmopathy. Thyroid Off J Am Thyroid Assoc 9: 305-310.

12. Förster G, Otto E, Hansen C, et al. (1998): Analysis of orbital $\mathrm{T}$ cells in thyroid-associated ophthalmopathy. Clin Exp Immunol 112: 427-434.

13. Pappa A, Calder V, Ajjan R, et al. (1997): Analysis of extraocular muscle-infiltrating T cells in thyroid-associated ophthalmopathy (TAO). Clin Exp Immunol 109: 362-369.

14. de Carli M, D'Elios MM, Mariotti S, et al. (1993): Cytolytic T cells with Th1-like cytokine profile predominate in retroorbital lymphocytic infiltrates of Graves' ophthalmopathy. J Clin Endocrinol Metab 77: 1120-1124.

15. Hiromatsu Y, Yang D, Bednarczuk T, et al. (2000): Cytokine profiles in eye muscle tissue and orbital fat tissue from patients with thyroid-associated ophthalmopathy. J Clin Endocrinol Metab 85: 1194-1199.

16. Aniszewski JP, Valyasevi RW, Bahn RS (2000): Relationship between disease duration and predominant orbital $\mathrm{T}$ cell subset in Graves' ophthalmopathy. J Clin Endocrinol Metab 85: 776-780.

17. Huang D, Luo Q, Yang H, et al. (2014): Changes of lacrimal gland and tear inflammatory cytokines in thyroid-associated ophthalmopathy. Invest Ophthalmol Vis Sci 55: 4935-4943.

18. Wei H, Guan M, Qin Y, et al. (2014): Circulating levels of miR-146a and IL-17 are significantly correlated with the clinical activity of Graves' ophthalmopathy. Endocr J 61: 10871092.

19. Song R, Qin Q, Wang X, et al. (2016): Differential cytokine expression detected by protein microarray screening in peripheral blood of patients with refractory Graves' disease. Clin Endocrinol (Oxf) 84: 402-407.
20. Nowak M, Siemińska L, Karpe J, et al. (2016): Serum concentrations of HGF and IL-8 in patients with active Graves' orbitopathy before and after methylprednisolone therapy. J Endocrinol Invest 39: 63-72.

21. Mysliwiec J, Palyga I, Nikolajuk A, et al. (2012): Serum interleukin-16 and RANTES during treatment of Graves' orbitopathy with corticosteroids and teleradiotherapy. Endokrynol Pol 63: 92-96.

22. Liang C, Du W, Dong Q, et al. (2015): Expression levels and genetic polymorphisms of interleukin-2 and interleukin-10 as biomarkers of Graves' disease. Exp Ther Med 9: 925-930.

23. Celik HT, Abusoglu S, Burnik SF, et al. (2013): Increased serum interleukin-33 levels in patients with Graves' disease. Endocr Regul 47: 57-64.

24. Nowak M, Wielkoszyński T, Kos-Kudła B, et al (2007): The blood concentration of intercellular adhesion molecule-1 (sICAM-1) and vascular cell adhesion molecule-1 (sVCAM-1) in patients with active thyroid-associated orbitopathy before and after methylprednisolone treatment. Endokrynol Pol 58: 487-491.

25. Li X, Qi Y, Ma X, et al. (2013): Chemokine (C-C motif) ligand 20, a potential biomarker for Graves' disease, is regulated by osteopontin. PloS One 8: e64277.

26. Reza S, Shaukat A, Arain TM, et al. (2013): Expression of osteopontin in patients with thyroid dysfunction. PloS One 8:e56533.

27. Esteghamati A, Khalilzadeh O, Mobarra Z, et al. (2009): Association of CTLA-4 gene polymorphism with Graves' disease and ophthalmopathy in Iranian patients. Eur J Intern Med 20: 424-428.

28. Frydecka I, Daroszewski J, Suwalska K, et al. (2004): CTLA4 (CD152) gene polymorphism at position 49 in exon 1 in Graves' disease in a Polish population of the Lower Silesian region. Arch Immunol Ther Exp (Warsz) 52: 369-374.

29. Khalilzadeh O, Noshad S, Rashidi A, et al. (2011): Graves' ophthalmopathy: a review of immunogenetics. Curr Genomics 12: 564-575.

30. Pawlowski P, Mysliwiec J, Mrugacz M, et al. (2014): Elevated percentage of HLA-DR ${ }^{+}$and ICAM- $1^{+}$conjunctival epithelial cells in active Graves' orbitopathy. Graefes Arch Clin Exp Ophthalmol Albrecht Von Graefes Arch Klin Exp Ophthalmol 252: 641-645.

31. Stenszky V, Kozma L, Balazs C, et al. (1983): HLA-DR associations with Graves' disease in eastern Hungary. Clin Investig Med Med Clin Exp 6: 181-184.

32. Planck T, Shahida B, Parikh H, et al. (2014): Smoking induces overexpression of immediate early genes in active Graves' ophthalmopathy. Thyroid Off J Am Thyroid Assoc 24: 15241532.

33. van Steensel L, Hooijkaas H, Paridaens D, et al. (2012): PDGF enhances orbital fibroblast responses to TSHR stimulating autoantibodies in Graves' ophthalmopathy patients. J Clin Endocrinol Metab 97: E944-953.

34. van Steensel L, Paridaens D, van Meurs M, et al. (2012): Orbit-infiltrating mast cells, monocytes, and macrophages produce PDGF isoforms that orchestrate orbital fibroblast activation in Graves' ophthalmopathy. J Clin Endocrinol Metab 97: E400-408.

35. Virakul S, van Steensel L, Dalm VASH, et al. (2014): Platelet-derived growth factor: a key factor in the pathogenesis of graves' ophthalmopathy and potential target for treatment. Eur Thyroid J 3: 217-226. 
36. van Steensel L, Paridaens D, Schrijver B, et al. (2009): Imatinib mesylate and AMN107 inhibit PDGF-signaling in orbital fibroblasts: a potential treatment for Graves' ophthalmopathy. Invest Ophthalmol Vis Sci 50: 3091-3098.

37. Virakul S, Dalm VASH, Paridaens D, et al. (2015): Platelet-Derived Growth Factor-BB Enhances Adipogenesis in Orbital Fibroblasts. Invest Ophthalmol Vis Sci 56: 5457-5464.

38. Lim HS, Back KO, Kim HJ, et al. (2014): Hyaluronic acid induces COX-2 expression via CD44 in orbital fibroblasts from patients with thyroid-associated ophthalmopathy. Invest Ophthalmol Vis Sci 55: 7441-7450.

39. Pawlowski P, Wawrusiewicz-Kurylonek N, Eckstein A, et al. (2015): Disturbances of modulating molecules (FOXP3, CTLA-4/CD28/B7, and CD40/CD40L) mRNA expressions in the orbital tissue from patients with severe graves' ophthalmopathy. Mediators Inflamm 2015: 340934.

40. Zhao LQ, Wei RL, Cheng JW, et al. (2010): The expression of intercellular adhesion molecule-1 induced by CD40CD40L ligand signaling in orbital fibroblasts in patients with Graves' ophthalmopathy. Invest Ophthalmol Vis Sci 51: 4652-4660.

41. Ezra DG, Krell J, Rose GE, et al. (2012): Transcriptome-level microarray expression profiling implicates IGF-1 and Wnt signalling dysregulation in the pathogenesis of thyroid-associated orbitopathy. J Clin Pathol 65: 608-613.

42. Sempowski G, Rozenblit J, Smith TJ, Phipps RP (1998): Human orbital fibroblasts are activated through CD40 to induce proinflammatory cytokine production. Am J Physiol Cell Physiol 274: C707-C714.

43. Hwang CJ, Afifiyan N, Sand D, et al. (2009): Orbital fibroblasts from patients with thyroid-associated ophthalmopathy overexpress CD40: CD154 hyperinduces IL-6, IL-8, and MCP-1. IOVS 50: 2262-2268.

44. Cao HJ, Wang HS, Zhang Y, et al. (1998): Activation of human orbital fibroblasts through CD40 engagement results in a dramatic induction of hyaluronan synthesis and prostaglandin endoperoxide $\mathrm{H}$ synthase-2 expression. Insights into potential pathogenic mechanisms of thyroid-associated ophthalmopathy. J Biol Chem 273: 29615-29625.

45. Smith TJ (2002): Orbital fibroblasts exhibit a novel pattern of responses to proinflammatory cytokines: potential basis for the pathogenesis of thyroid-associated ophthalmopathy. Thyroid Off J Am Thyroid Assoc 12: 197-203.

46. Wang HS, Cao HJ, Winn VD, et al. (1996): Leukoregulin induction of prostaglandin-endoperoxide $\mathrm{H}$ synthase-2 in human orbital fibroblasts. An in vitro model for connective tissue inflammation. J Biol Chem 271: 22718-22728.

47. Young DA, Evans CH, Smith TJ (1998): Leukoregulin induction of protein expression in human orbital fibroblasts: evidence for anatomical site-restricted cytokine-target cell interactions. Proc Natl Acad Sci U S A 95: 8904-8909.

48. Han R, Tsui S, Smith TJ (2002): Up-regulation of prostaglandin E2 synthesis by interleukin-1beta in human orbital fibroblasts involves coordinate induction of prostaglandin-endoperoxide $\mathrm{H}$ synthase-2 and glutathione-dependent prostaglandin E2 synthase expression. J Biol Chem 277: 1635516364 .

49. Chen B, Tsui S, Boeglin WE, et al. (2006): Interleukin-4 induces 15-lipoxygenase-1 expression in human orbital fibroblasts from patients with Graves disease. Evidence for anatomic site-selective actions of Th2 cytokines. J Biol Chem 281: 18296-18306.
50. Sciaky D, Brazer W, Center DM, et al. (2000): Cultured human fibroblasts express constitutive IL-16 mRNA: cytokine induction of active IL-16 protein synthesis through a caspase-3-dependent mechanism. J Immunol 164: 38063814.

51. Han R, Smith TJ (2006): T helper type 1 and type 2 cytokines exert divergent influence on the induction of prostaglandin E2 and hyaluronan synthesis by interleukin-1beta in orbital fibroblasts: implications for the pathogenesis of thyroid-associated ophthalmopathy. Endocrinology 147: 13-19.

52. Han R, Chen B, Smith TJ (2007): Jak2 dampens the induction by IL-1beta of prostaglandin endoperoxide $\mathrm{H}$ synthase 2 expression in human orbital fibroblasts: evidence for divergent influence on the prostaglandin E2 biosynthetic pathway. J Immunol 179: 7147-7156.

53. Tsui S, Fernando R, Chen B, et al. (2011): Divergent Sp1 protein levels may underlie differential expression of UDP-glucose dehydrogenase by fibroblasts: role in susceptibility to orbital Graves disease. J Biol Chem 286: 24487-24499.

54. Koumas L, Smith TJ, Feldon S, et al. (2003): Thy-1 expression in human fibroblast subsets defines myofibroblastic or lipofibroblastic phenotypes. Am J Pathol 163: 1291-1300.

55. Douglas RS, Afifiyan NF, Hwang CJ, et al. (2010): Increased generation of fibrocytes in thyroid-associated ophthalmopathy. J Clin Endocrinol Metab 95: 430-438.

56. Gillespie EF, Papageorgiou KI, Fernando R, et al. (2012): Increased expression of TSH receptor by fibrocytes in thyroid-associated ophthalmopathy leads to chemokine production. J Clin Endocrinol Metab 97: E740-746.

57. Gerding MN, van der Meer JW, Broenink M, et al. (2000): Association of thyrotrophin receptor antibodies with the clinical features of Graves' ophthalmopathy. Clin Endocrinol (Oxf) 52: 267-271.

58. Eckstein AK, Plicht M, Lax H, et al. (2006): Thyrotropin receptor autoantibodies are independent risk factors for Graves' ophthalmopathy and help to predict severity and outcome of the disease. J Clin Endocrinol Metab 91: 3464-3470.

59. Lytton SD, Ponto KA, Kanitz M, et al. (2010): A novel thyroid stimulating immunoglobulin bioassay is a functional indicator of activity and severity of Graves' orbitopathy. J Clin Endocrinol Metab 95: 2123-2131.

60. Tsui S, Naik V, Hoa N, et al. (2008): Evidence for an association between thyroid-stimulating hormone and insulin-like growth factor 1 receptors: a tale of two antigens implicated in Graves' disease. J Immunol 181:4397-4405.

61. Parmentier M, Libert F, Maenhaut C, et al. (1989): Molecular cloning of the thyrotropin receptor. Science 246: 1620-1622.

62. Sanders J, Chirgadze DY, Sanders P, et al. (2007): Crystal structure of the TSH receptor in complex with a thyroid-stimulating autoantibody. Thyroid Off J Am Thyroid Assoc 17: 395-410.

63. Sanders P, Young S, Sanders J, et al. (2011): Crystal structure of the TSH receptor (TSHR) bound to a blocking-type TSHR autoantibody. J Mol Endocrinol 46: 81-99.

64. Kleinau G, Krause G (2009): Thyrotropin and homologous glycoprotein hormone receptors: structural and functional aspects of extracellular signaling mechanisms. Endocr Rev 30: 133-151.

65. Rapoport B, Aliesky HA, Chen C-R, McLachlan SM (2015): Evidence that TSH Receptor A-Subunit Multimers, Not Monomers, Drive Antibody Affinity Maturation in Graves' Disease. J Clin Endocrinol Metab 100: E871-875. 
66. Cornelis S, Uttenweiler-Joseph S, Panneels V, et al. (2001): Purification and characterization of a soluble bioactive amino-terminal extracellular domain of the human thyrotropin receptor. Biochemistry 40: 9860-9869.

67. Rapoport B, McLachlan SM (2016): TSH Receptor Cleavage Into Subunits and Shedding of the A-Subunit; A Molecular and Clinical Perspective. Endocr Rev 37: 114-134.

68. Bahn RS (2015): Current Insights into the Pathogenesis of Graves' Ophthalmopathy. Horm Metab Res Horm Stoffwechselforschung Horm Metab 47: 773-778.

69. Bahn RS (2002): Thyrotropin receptor expression in orbital adipose/connective tissues from patients with thyroid-associated ophthalmopathy. Thyroid Off J Am Thyroid Assoc 12: 193-195.

70. Ludgate M, Crisp M, Lane C, et al. (1998): The thyrotropin receptor in thyroid eye disease. Thyroid Off J Am Thyroid Assoc 8: 411-413.

71. Crisp MS, Lane C, Halliwell M, et al. (1997): Thyrotropin receptor transcripts in human adipose tissue. J Clin Endocrinol Metab 82: 2003-2005.

72. Wakelkamp IMMJ, Bakker O, Baldeschi L, et al. (2003): TSH-R expression and cytokine profile in orbital tissue of active vs. inactive Graves' ophthalmopathy patients. Clin Endocrinol (Oxf) 58: 280-287.

73. Zhang L, Bowen T, Grennan-Jones F, et al. (2009): Thyrotropin receptor activation increases hyaluronan production in preadipocyte fibroblasts: contributory role in hyaluronan accumulation in thyroid dysfunction. J Biol Chem 284: 2644726455.

74. Kumar S, Schiefer R, Coenen MJ, et al. (2010): A stimulatory thyrotropin receptor antibody (M22) and thyrotropin increase interleukin-6 expression and secretion in Graves' orbital preadipocyte fibroblasts. Thyroid Off J Am Thyroid Assoc 20: 59-65.

75. Petersen JC, Kaiser S, Dean N, et al. (2011): Clocking the melting transition of charge and lattice order in 1T-TaS2 with ultrafast extreme-ultraviolet angle-resolved photoemission spectroscopy. Phys Rev Lett 107: 177402.

76. Boutin A, Eliseeva E, Gershengorn MC, et al. (2014): $\beta$-Arrestin-1 mediates thyrotropin-enhanced osteoblast differentiation. FASEB J Off Publ Fed Am Soc Exp Biol 28: 3446-3455.

77. Frenzel R, Voigt C, Paschke R (2006): The human thyrotropin receptor is predominantly internalized by beta-arrestin 2 . Endocrinology 147: 3114-3122.

78. Smith TJ (2010): Insulin-like growth factor-I regulation of immune function: a potential therapeutic target in autoimmune diseases? Pharmacol Rev 62: 199-236.

79. Girnita L, Worrall C, Takahashi S-I, et al. (2014): Something old, something new and something borrowed: emerging paradigm of insulin-like growth factor type 1 receptor (IGF-1R) signaling regulation. Cell Mol Life Sci CMLS 71: 2403-2427.

80. Gallagher EJ, LeRoith D (2011): Minireview: IGF, Insulin, and Cancer. Endocrinology 152: 2546-2551.

81. Pritchard J, Han R, Horst N, et al. (2003): Immunoglobulin activation of $\mathrm{T}$ cell chemoattractant expression in fibroblasts from patients with Graves' disease is mediated through the insulin-like growth factor I receptor pathway. J Immunol 170: 6348-6354

82. Pritchard J, Horst N, Cruikshank W, et al. (2002): Igs from patients with Graves' disease induce the expression of $\mathrm{T}$ cell chemoattractants in their fibroblasts. J Immunol 168: 942-950.
83. Tramontano D, Cushing GW, Moses AC, et al. (1986): Insulin-like growth factor-I stimulates the growth of rat thyroid cells in culture and synergizes the stimulation of DNA synthesis induced by TSH and Graves'-IgG. Endocrinology 119: 940-942.

84. Khong JJ, McNab AA, Ebeling PR, et al. (2016): Pathogenesis of thyroid eye disease: review and update on molecular mechanisms. Br J Ophthalmol 100: 142-150.

85. Hoa N, Tsui S, Afifiyan NF, et al. (2012): Nuclear targeting of IGF-1 receptor in orbital fibroblasts from Graves' disease: apparent role of ADAM17. PloS One 7: e34173.

86. Krieger CC, Neumann S, Marcus-Samuels B, et al. (2017): TSHR/IGF-1R Cross-talk, not IGF-1R stimulating antibodies, mediates Graves' Ophthalmopathy pathogenesis. Thyroid Off J Am Thyroid Assoc 27: 746-747.

87. Chen H, Mester T, Raychaudhuri N, et al. (2014): Teprotumumab, an IGF-1R blocking monoclonal antibody inhibits TSH and IGF-1 action in fibrocytes. J Clin Endocrinol Metab 99: E1635-1640.

88. Neumann S, Huang W, Eliseeva E, et al. (2010): A small molecule inverse agonist for the human thyroid-stimulating hormone receptor. Endocrinology 151: 3454-3459.

89. Turcu AF, Kumar S, Neumann S, et al. (2013): A small molecule antagonist inhibits thyrotropin receptor antibody-induced orbital fibroblast functions involved in the pathogenesis of Graves ophthalmopathy. J Clin Endocrinol Metab 98: 21532159.

90. Neumann S, Pope A, Geras-Raaka E, et al. (2012): A druglike antagonist inhibits thyrotropin receptor-mediated stimulation of cAMP production in Graves' orbital fibroblasts. Thyroid Off J Am Thyroid Assoc 22: 839-843. 